\title{
pS6K1 as an efficacy marker of GnRH agonist with premenopausal breast cancer
}

\author{
Chan Sub Park ${ }^{1}$, Jihye Choi ${ }^{2}$, Min-Ki Seong ${ }^{3}$, Sung-Eun Hong ${ }^{4}$, Jae-Sung Kim ${ }^{4}$, In-Chul Park ${ }^{5}$, Hyesil Seol' \\ Woo Chul Noh ${ }^{3}$ and Hyun-Ah Kim ${ }^{3}$
}

'Department of Breast and Thyroid Surgery, Kyungpook National University Chilgok Hospital, Buk-gu, Daegu, Republic of Korea ${ }^{2}$ Department of General Surgery, National Medical Center, Jung-gu, Seoul, Republic of Korea

${ }^{3}$ Department of Surgery, Korea Cancer Center Hospital, Korea Institute of Radiological and Medical Sciences, Nowon-gu, Seoul, Republic of Korea

${ }^{4}$ Radiation Medicine Clinical Research Division, Korea Institute of Radiological and Medical Sciences, Nowon-gu, Seoul, Republic of Korea

${ }^{5}$ Division of Fusion Radiology Research, Korea Institute of Radiological and Medical Sciences, Nowon-gu, Seoul, Republic of Korea

${ }^{6}$ Department of Pathology, Korea Cancer Center Hospital, Korea Institute of Radiological and Medical Sciences, Nowon-gu, Seoul, Republic of Korea

Correspondence should be addressed to H-A Kim: hyunah@kcch.re.kr

\begin{abstract}
Estradiol is a key factor for tumorigenesis and prognosis of hormone receptor-positive breast cancer. Adipocytes are one source of estradiol in patients with breast cancer. Recent studies have shown that phosphorylated ribosomal protein 56 kinase-1 plays a critical role in adipogenesis. Therefore, estrogen depletion therapy might have beneficial effects in phosphorylated ribosomal protein $\mathbf{S 6}$ kinase-1-positive breast cancer. This study was conducted to evaluate the value of phosphorylated ribosomal protein $\mathrm{S6}$ kinase-1 as a marker for gonadotropin-releasing hormone agonist treatment, a form of estrogen depletion therapy, for premenopausal patients with HR-positive, human epidermal growth factor receptor 2-negative breast cancer. We reviewed the medical records of 296 premenopausal patients with hormone receptor-positive, human epidermal growth factor receptor 2-negative primary invasive breast cancer treated between 2008 and 2015. Phosphorylated ribosomal protein S6 kinase-1 positivity was defined by immunohistochemical staining scores of $1+, 2+$ and $3+$, whereas a score of 0 was considered negative. Phosphorylated ribosomal protein 66 kinase-1-positive tumors were found in $74.0 \%$ of the patients. In the phosphorylated ribosomal protein $\mathrm{S} 6$ kinase-1-positive group, disease-free survival of patients treated with a gonadotropinreleasing hormone agonist was significantly longer than that of patients treated without a gonadotropin-releasing hormone agonist (mean 106.7 months vs mean 91.1 months, $P=0.018$ ). Phosphorylated ribosomal protein $\mathrm{S} 6$ kinase-1 is a potential biomarker for predicting the efficacy of gonadotropin-releasing hormone agonist therapy in premenopausal patients with hormone receptor-positive, human epidermal growth factor receptor 2-negative breast cancer.
\end{abstract}
Key Words
- breast cancer
- treatment efficacy
- ribosomal protein S6 kinase 1
- GnRH agonist

\section{Introduction}

Estradiol is a key factor for tumorigenesis and prognosis of hormone receptor (HR)-positive breast cancer. Although estradiol is produced mainly by the ovary in premenopausal women, the adrenal gland and adipocytes are also sources of lesser amounts of estradiol $(1,2,3)$.
Therefore, obesity, a medical condition with excess adipose tissue, has been explored as a risk factor and prognosis marker for a poor outcome in patients with HR-positive breast cancer. The effect of obesity on the prognosis of breast cancer is magnified in menopausal https://ec.bioscientifica.com

https://doi.org/10.1530/EC-19-0101 (c) 2019 The authors Published by Bioscientifica Ltd

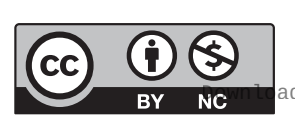

This work is licensed under a Creative Commons Attribution-NonCommercial 4.0 International License. ded from Bioscientifica.com at 04/26/2023 02:16:30PM 
women and those with suppressed ovarian function. Importantly, the prognosis of menopausal patients with breast cancer is affected by obesity; this might arise from elevated aromatase in adipose tissue $(4,5,6,7,8)$.

Phosphorylated ribosomal protein S6 kinase-1 (pS6K1) is an effector of mammalian target of rapamycin activity in tumors and was recently identified as a biomarker for adipogenesis in the field of obesity (9). Theoretically, high expression of S6K1 in a tumor may be related to adipogenesis on the tumor itself or in the tumor micro-environment and may stimulate the local estradiol concentration $(10,11,12)$. In our previous study, pS6K1 overexpression was associated with a worse prognosis in HR-positive breast cancer (13). The study included patients that underwent surgery between January 1999 and January 2002. During that period, selective estrogen receptor modulator (SERM) treatment was the only adjuvant endocrine therapy regimen that was reimbursed by the national health insurance in South Korea for HR-positive breast cancer. Consequently, the majority of patients included in that analysis were treated by adjuvant SERM monotherapy, without any estradiol depletion regimen regardless of menopausal status (13).

In several recent pre-clinical studies, estradiol suppresses adipogenesis and activates brown adipose tissue $(14,15)$. It might be a mechanism of action of estrogen replacement therapy, which has a beneficial effect on reducing cerebrovascular events in healthy postmenopausal women. However, concerning the breast cancer, the excess exposure to the high level of estradiol such as has long-term hormone replacement therapy, early menarche, late menopause or obesity has been suspected as risk factors of the hormone susceptible breast cancer (16). Once the breast cancer developed, the breast adipose tissue bearing a tumor overexpresses aromatase, leading to local overproduction of estrogen that exerts paracrine and intracrine tumorigenic effects (17). As a consequence of the process, the level of estradiol in tumor of breast cancer is significantly higher compared with circulating level in 18, 19.

Tamoxifen is a representative SERM. It functions as a competitive partial agonist for the estrogen receptor. The antitumor effect of tamoxifen is diminished when the estradiol level is high (20). We assumed that the poor prognosis of patients with pS6K1-positive tumors who were treated by an adjuvant SERM was caused by the high local estradiol level resulting from local adipogenesis based on a recent report about pS6K1 and obesity (9). In addition, we hypothesized that estradiol depletion therapy might be more effective in patients with pS6K1positive than -negative tumors.

Estrogen depletion therapy was developed for treating HR-positive breast cancer in recent decades. Gonadotropin-releasing hormone $(\mathrm{GnRH})$ agonists are specific estradiol depletion therapy for premenopausal women. According to the ESO-ESMO 3rd International Consensus Guidelines for treating breast cancer in young women, ovarian function suppression is recommended. However, they also recommend that this treatment be given only if it is tolerable (21). Menopausal symptoms caused by a GnRH agonist could decrease the tolerability of this treatment. In addition, GnRH agonists can have adverse effects on bone health. For these reasons, a marker for the efficacy of GnRH agonists is required. In this study, we evaluated the effect of a GnRH agonist on disease-free survival based on the expression of pS6K1 in women with HR-positive, human epithelial growth factor 2 (HER2)negative breast cancer.

\section{Methods}

In this retrospective study, we included premenopausal women under 45 years of age with HR-positive, HER2negative breast cancer. Patients with a history of other primary malignancies and de novo stage IV breast cancer were excluded. Patients who received adjuvant cyclophosphamide, methotrexate and fluorouracil (CMF) therapy were also excluded because of the higher rate of chemotherapy-induced amenorrhea $(22,23)$. Values for analyses were obtained from the patients' medical records. These included immunohistochemical analyses for pS6K1 expression, HR status and HER2 status, and other clinical factors (i.e., age at the time of diagnosis, tumor size, lymph node status, mammographic density and patient outcomes). This study was approved by the Institutional Review Board of Korea Cancer Center Hospital (IRB No. 2017-12-010). Informed consent was waived because this was retrospective study.

Immunohistochemical staining of the estrogen, progesterone and HER2 receptors, and pS6K1 was performed on core needle biopsy specimens obtained at the time of diagnosis or surgical specimens obtained at the time of curative surgery. Mouse monoclonal antibodies against human pS6K1 (Cell Signaling Technology; dilution 1:50), and estrogen, progesterone and HER2 receptors, were used as the primary antibodies (13). Experienced pathologists interpreted the immunoreactivity of all https://ec.bioscientifica.com https://doi.org/10.1530/EC-19-0101 (c) 2019 The authors Published by Bioscientifica Ltd
This work is licensed under a Creative Commons Attribution-NonCommercial 4.0 International License. ded from Bioscientifica.com at 04/26/2023 02:16:30PM 
results including pS6K1 expression. Results were reported officially and included in the medical records as a routine clinical practice. The expression of pS6k1 was categorized according to the immunohistochemical stain on cytosol or nucleus of tumor cells, and the stain was expressed on both nucleus and cytosol in majority of the cases. The pS6K1 expression status was scored from 0 to $3+$; in this study, we classified $1+$ to $3+$ as positive and 0 as negative. Estrogen and progesterone receptor expression was calculated by the intensity score. A score of 0 was regarded as negative, while other scores were regarded as positive. HER 2 expression was defined according to the American Society of Clinical Oncology/College of American Pathologists Clinical Practice Guideline (24). HER2 expression was scored from 0 to $3+$. Scores of 0 and $1+$ were classified as a negative reaction and $3+$ was classified as a positive reaction. In situ hybridization was performed when immunohistochemistry showed a $2+$ or greater result.

Mammographic breast density of patients was interpreted and reported officially by an experienced radiologist. The Breast Imaging Reporting and Data System for Breast Density Classification was used to define each group. Briefly, when glandular tissue was less than $25 \%$, it was defined as grade 1 . Glandular tissue of grade 2 ranged from 25 to $50 \%$ of the breast. Grade 3 represented heterogeneously dense breast tissue where the parenchyma ranged from 51 to $75 \%$. Grade 4 contained more than $75 \%$ glandular and fibrous tissue (25). Breast density reports were included in all medical records.

Pearson's chi-square test was used to assess the correlation between pS6K1 expression and other variables. Disease-free survival was defined as the time from diagnosis to the first event ending disease-free survival including locoregional recurrence, distant relapse, contralateral breast cancer, other primary cancer or death from any other cause. Survival analysis was constructed using the Kaplan-Meier method and differences were assessed using the log-rank test. Statistical significance was accepted for a $P$ value of $<0.05$.

\section{Results}

\section{Patient characteristics}

A total of 296 patients were eligible for this analysis. The median follow-up period was 49.0 months (range: 1-114 months). Clinicopathological characteristics of the patients are listed in Table 1. Two hundred nineteen patients were categorized as pS6K1 positive (74.0\%). The pS6K1positive and -negative groups were well balanced in tumor size, nodal metastasis status, Ki67 status, surgical methods, BMI, serum estradiol levels and serum follicle-stimulating hormone levels at the time of diagnosis. There was no significant difference in BMI between the groups (Table 1).

Table 1 Clinicopathologic characteristics of patients.

\begin{tabular}{|c|c|c|c|c|}
\hline & & & & \\
\hline & & Positive $(n=219)$ & Negative $(n=77)$ & $P$ value \\
\hline Age (years, median) & & 42.0 & 42.0 & 0.479 \\
\hline Body mass index $\left(\mathrm{kg} / \mathrm{m}^{2}\right.$, median $)$ & $<25$ & $171(78.1 \%)$ & $56(72.7 \%)$ & 0.339 \\
\hline & $\geq 25$ & $48(21.9 \%)$ & $21(27.3 \%)$ & \\
\hline Serum estradiol (mIU/mL, median) & & 89.3 & 67.5 & 0.495 \\
\hline Follicle-stimulating hormone $(\mathrm{pg} / \mathrm{m}$ & dian) & 5.84 & 5.76 & 0.961 \\
\hline Ki67 (\%, median) & & 5.00 & 5.00 & 0.569 \\
\hline Tumor size & $<2 \mathrm{~cm}$ & $139(63.5 \%)$ & $51(66.2 \%)$ & 0.664 \\
\hline & $\geq 2 \mathrm{~cm}$ & 80 (36.5\%) & 26 (33.8\%) & \\
\hline Lymph node metastasis & $\bar{N}$ egative & $133(60.7 \%)$ & $44(57.1 \%)$ & 0.581 \\
\hline & Positive & $86(39.3 \%)$ & $33(42.9 \%)$ & \\
\hline Breast operation & Breast-conserving surgery & $147(67.1 \%)$ & $58(75.3 \%)$ & 0.180 \\
\hline & Total mastectomy & $72(32.9 \%)$ & $19(24.7 \%)$ & \\
\hline Adjuvant radiotherapy & Yes & $184(84.0 \%)$ & $63(81.8 \%)$ & 0.655 \\
\hline & No & $35(16.0 \%)$ & $14(18.2 \%)$ & \\
\hline Chemotherapy & No & $74(33.8 \%)$ & $37(48.1 \%)$ & 0.024 \\
\hline & Regimen with taxane & $80(36.5 \%)$ & $28(36.4 \%)$ & \\
\hline & Regimen without taxane & $65(29.7 \%)$ & $12(15.6 \%)$ & \\
\hline Endocrine therapy & Tamoxifen only & $108(49.3 \%)$ & $23(29.9 \%)$ & 0.003 \\
\hline & Tamoxifen $+\mathrm{GnRH}$ agonist & $111(50.7 \%)$ & $54(70.1 \%)$ & \\
\hline
\end{tabular}

https://ec.bioscientifica.com

https://doi.org/10.1530/EC-19-0101 (c) 2019 The authors Published by Bioscientifica Ltd

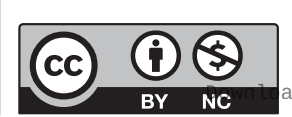

This work is licensed under a Creative Commons Attribution-NonCommercial 4.0 International License. ded from Bioscientifica.com at 04/26/2023 02:16:30PM via free access 
The relationship between breast density and pS6K1 expression was analyzed. Of the pS6K1-positive patients, $46.6 \%$ exhibited grade 4 mammographic breast density, while only $28.6 \%$ of the pS6K1-negative group had this density $(P=0.013$, Fig. 1$)$.

\section{Disease-free survival according to the use of a GnRH agonist}

In pS6K1-positive patients treated with tamoxifen plus a GnRH agonist, disease-free survival was better than the tamoxifen-only group (hazard ratio $0.280, P=0.018$; Fig. 2A). The mean survival of the GnRH agonist group was 106.7 months and that of the tamoxifen only group was 91.1 months. In contrast, GnRH usage did not show significant clinical benefits in terms of disease-free survival in pS6K1-negative patients (hazard ratio $0.488, P=0.464$; Fig. 2B). Large tumor size and lymph node metastasis were related with poorer disease-free survival (Table 2).

\section{Discussion}

In this study, pS6K1-positive patients treated with a GnRH agonist plus tamoxifen showed better disease-free survival than those given tamoxifen alone. In contrast, there was no significant difference regarding disease-free survival based on GnRH agonist treatment in pS6K1-negative patients. The percentage of pS6K1-positive patients with grade 4 breast density was higher than that in pS6K1negative patients. Taken together, these findings indicate that pS6K1 may be considered a predictive marker for GnRH agonist efficacy in premenopausal women with

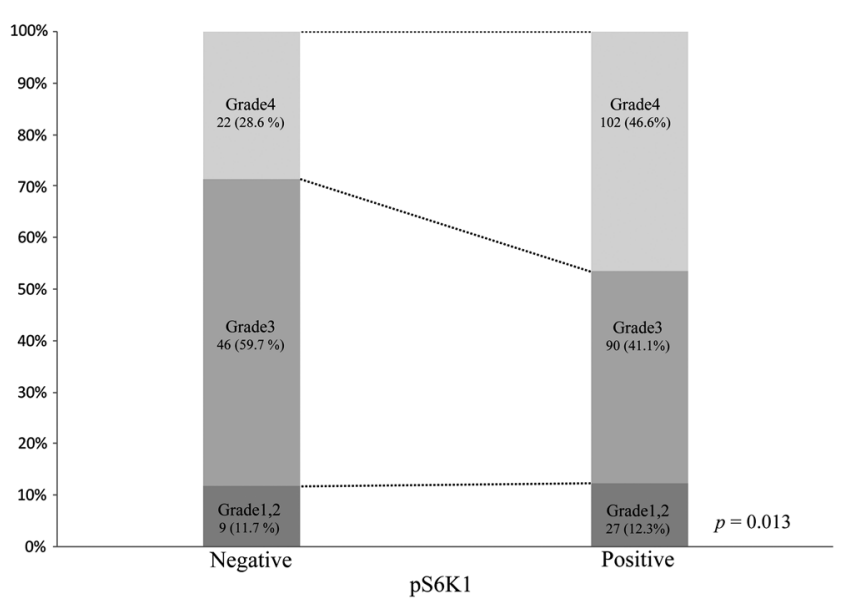

Figure 1

Breast density based on pS6K1 expression.
HR-positive breast cancer and might correlate with the local estradiol level. To the best of our knowledge, this is the first study showing the clinical value of pS6K1 as a predictive biomarker for an endocrine therapy regimen in premenopausal patients.

Although we demonstrated the efficacy of pS6K1 as a biomarker for estrogen depletion treatment in premenopausal women, the exact mechanism is not well supported by pre-clinical studies $(26,27)$. In the breast cancer field, pS6K1 is considered to be a marker for proliferation (28). In contrast, in the field of obesity,
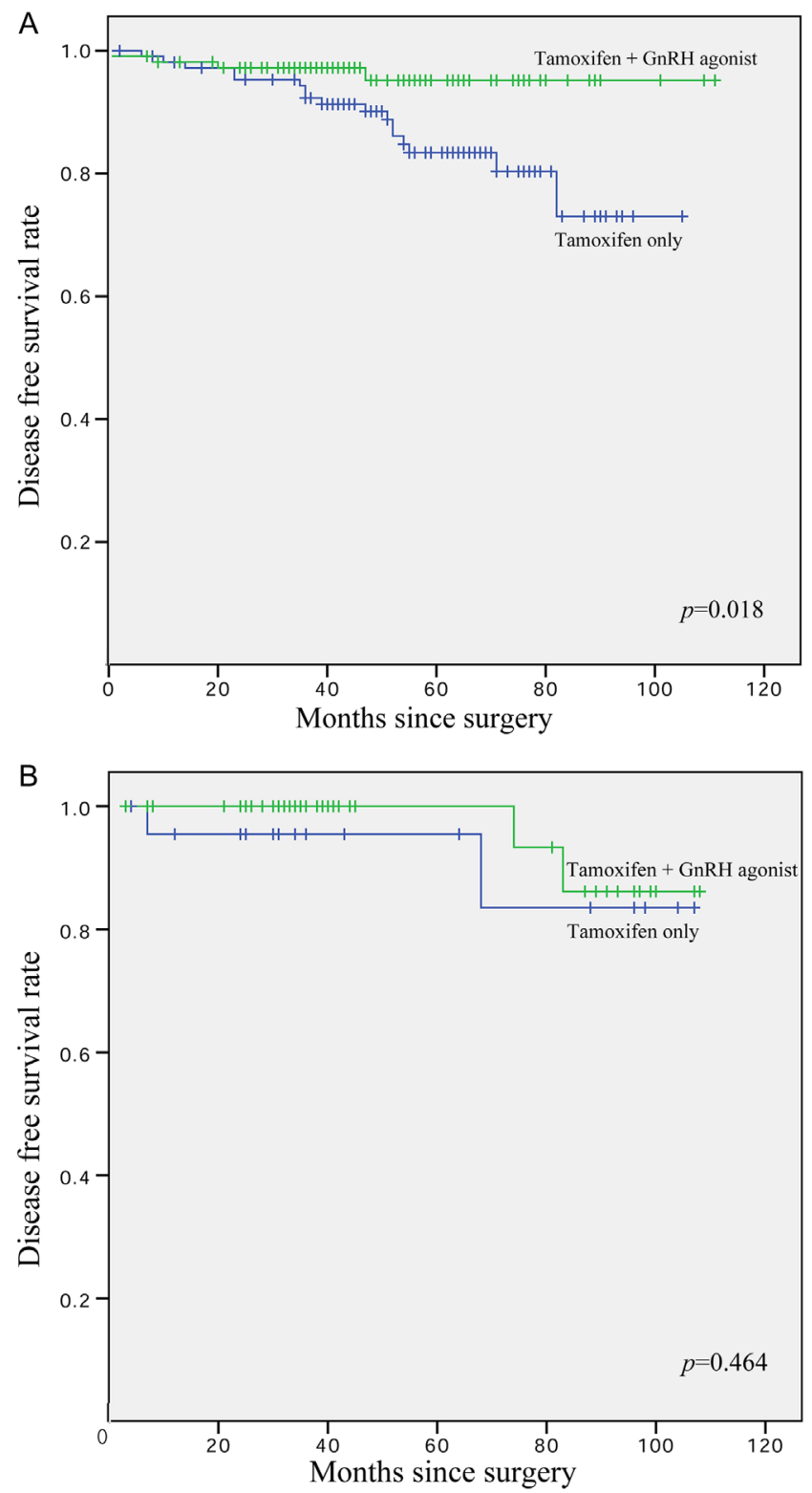

Figure 2

Kaplan-Meier plots for disease-free survival comparing $\mathrm{GnRH}$ agonist usage in pS6K1-positive group (A), pS6K1-negative group (B).

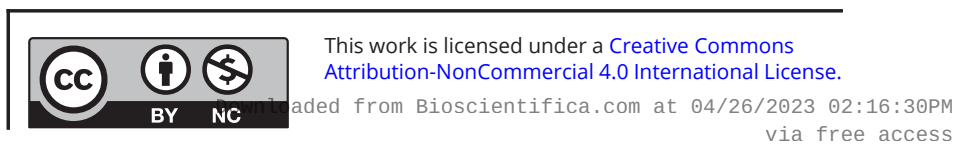




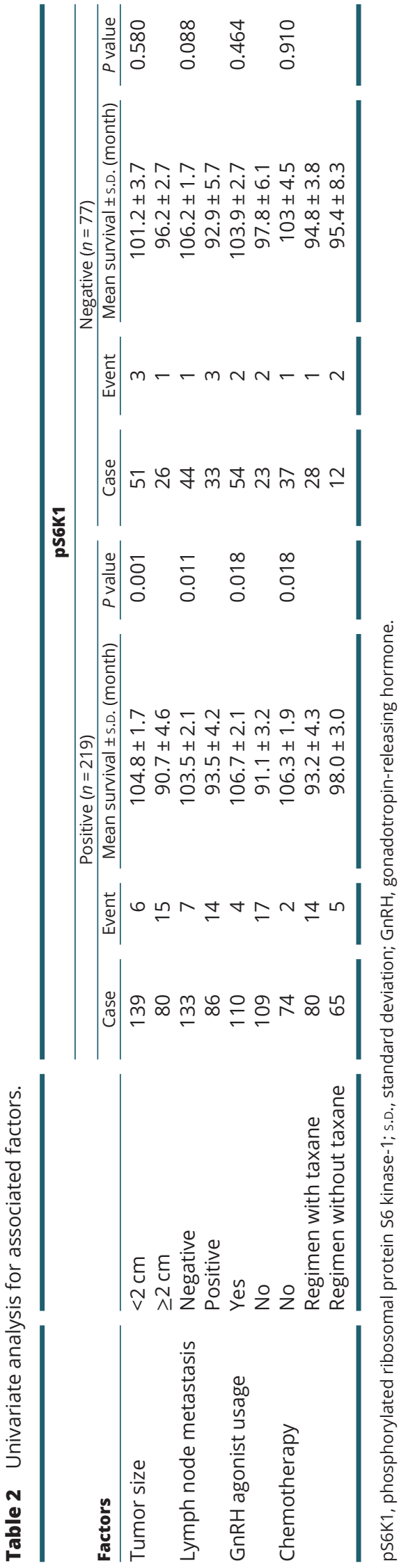

https://ec.bioscientifica.com https://doi.org/10.1530/EC-19-0101

(c) 2019 The authors Published by Bioscientifica Ltd it is considered to be a key molecule in adipogenesis $(29,30,31)$. We hypothesized that pS6K1 might have an adipogenic effect on tumors or the tumor microenvironment and as a consequence might be involved with a local increase of estradiol levels (32). Our current study demonstrated that breast tissue is relatively dense in patients with pS6K1-positive tumors. Because the relationship between breast density and the estradiol level is known, we hypothesized that dense breast tissue might be exposed to higher local estradiol levels that could arise because of pS6K1 positivity in HR-positive breast cancer.

The improved efficacy of adding a GnRH agonist in premenopausal women was elucidated by prospective randomized clinical trials such as the Suppression of Ovarian Function Trial (SOFT) and Addition of Ovarian Suppression to Tamoxifen in Young Women with HormoneSensitive Breast Cancer Who Remain Premenopausal or Regain Menstruation After Chemotherapy (ASTRRA) trial $(33,34)$. In SOFT, the 8-year disease-free survival rate was $78.9 \%$ with tamoxifen alone and $83.2 \%$ with tamoxifen plus ovarian suppression $(P=0.009)$. The 8 -year overall survival rate was $91.5 \%$ with tamoxifen alone and $93.3 \%$ with tamoxifen plus ovarian suppression $(P=0.010)$ (34). In the ASTRRA trial, the 5-year disease-free survival rate was $91.1 \%$ in the tamoxifen plus ovarian function suppression group and $87.5 \%$ in the tamoxifen only group $(P=0.033)$. The estimated overall survival rate after 5 years was $99.4 \%$ in the tamoxifen plus ovarian function suppression group and $97.8 \%$ in the tamoxifen only group $(P=0.029)$ (33). However, GnRH agonist treatment can cause adverse events such as osteoporosis or menopausal symptoms $(35,36,37)$. Therefore, determining which patients may receive beneficial effects from GnRH agonist therapy should be evaluated carefully, and pS6k1 might be a clinically helpful marker.

A strength of our study was in the exclusion of patients treated with the CMF regimen. Earlier studies reported amenorrhea during adjuvant chemotherapy, and the CMF regimen can induce permanent amenorrhea frequently $(22,23)$. Because our study analyzed the effect of ovarian function suppression, chemotherapy-induced amenorrhea could have been a bias for the interpretation of our results. Moreover, we included only patients below 45 years of age at diagnosis, which was similar to the study population of the ASTRRA trial. In that trial, 57.5\% of the patients treated by standard chemotherapy, except the CMF regimen, retained or regained ovarian function within 2 years of the completion of chemotherapy (33). PS6K1 status is easy to obtain by immunohistochemistry. Another strong point of this analysis was the classification

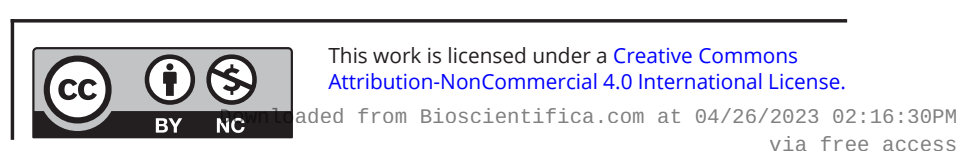


of pS6K1 expression on a $0-3+$ scale. In our study, we set $1+-3+$ as positive and 0 as negative and took measures to avoid bias from interpretation of the pS6K1 status.

A limitation of this study was its retrospective design that was conducted in a single institute. However, similar to many other biomarkers that are now used clinically in many kinds of tumors, results from this study provide helpful evidence to support conducting a prospective randomized controlled trial to evaluate precise endocrine therapy for premenopausal women with HR-positive, HER2-negative breast cancer.

In conclusion, pS6K1 is a potential biomarker for predicting the efficacy of GnRH agonist therapy in premenopausal patients with HR-positive, HER2-negative breast cancer. In such patients, estrogen depletion therapy, such as a GnRH agonist, might be offered more proactively.

\section{Declaration of interest}

The authors declare that there is no conflict of interest that could be perceived as prejudicing the impartiality of the research reported.

\section{Funding}

This study was supported by a grant of the Korea Institute of Radiological and Medical Science (KIRAMS), funded by Ministry of Science and ICT (MSIT), Republic of Korea (50472-2019).

\section{References}

1 Jiralerspong S \& Goodwin PJ. Obesity and breast cancer prognosis: evidence, challenges, and opportunities. Journal of Clinical Oncology 201634 4203-4216. (https://doi.org/10.1200/JCO.2016.68.4480)

2 Lauby-Secretan B, Scoccianti C, Loomis D, Grosse Y, Bianchini F, Straif K \& International Agency for Research on Cancer Handbook Working Group. Body fatness and cancer - viewpoint of the IARC Working Group. New England Journal of Medicine 2016375 794-798. (https://doi.org/10.1056/NEJMsr1606602)

3 Chan DSM, Vieira AR, Aune D, Bandera EV, Greenwood DC, Mctiernan A, Navarro Rosenblatt D, Thune I, Vieira R \& Norat T. Body mass index and survival in women with breast cancer systematic literature review and meta-analysis of 82 follow-up studies. Annals of Oncology 201425 1901-1914. (https://doi. org/10.1093/annonc/mdu042)

4 Cleary MP \& Grossmann ME. Minireview: Obesity and breast cancer: the estrogen connection. Endocrinology 2009150 2537-2542. (https://doi.org/10.1210/en.2009-0070)

5 Bulun SE, Lin Z, Imir G, Amin S, Demura M, Yilmaz B, Martin R, Utsunomiya H, Thung S, Gurates B, et al. Regulation of aromatase expression in estrogen-responsive breast and uterine disease: from bench to treatment. Pharmacological Reviews 200557 359-383. (https://doi.org/10.1124/pr.57.3.6)

6 Morris PG, Hudis CA, Giri D, Morrow M, Falcone DJ, Zhou XK, Du B, Brogi B, Crawford E, et al. Inflammation and increased aromatase expression occur in the breast tissue of obese women with breast cancer. Cancer Prevention Research 20114 1021-1029. (https://doi. org/10.1158/1940-6207.CAPR-11-0110)
7 Protani M, Coory M \& Martin JH. Effect of obesity on survival of women with breast cancer: systematic review and meta-analysis. Breast Cancer Research and Treatment 2010123 627-635. (https://doi. org/10.1007/s10549-010-0990-0)

8 Harvie M, Hooper L \& Howell AH. Central obesity and breast cancer risk: a systematic review. Obesity Reviews 20034 157-173. (https:// doi.org/10.1046/j.1467-789X.2003.00108.x)

9 van der Hage JA, van den Broek LJ, Legrand C, Clahsen PC, Bosch CJ, Robanus-Maandag EC, van de Velde CJ \& van de Vijver MJ. Overexpression of P70 S6 kinase protein is associated with increased risk of locoregional recurrence in node-negative premenopausal early breast cancer patients. British Journal of Cancer 200490 1543-1550. (https://doi.org/10.1038/sj.bjc.6601741)

10 Husseinzadeh $\mathrm{N} \&$ Husseinzadeh HD. mTOR inhibitors and their clinical application in cervical, endometrial and ovarian cancers: a critical review. Gynecologic Oncology 2014133 375-381. (https://doi. org/10.1016/j.ygyno.2014.02.017)

11 Zhou J, Gurates B, Yang S, Sebastian S \& Bulun SE. Malignant breast epithelial cells stimulate aromatase expression via promoter II in human adipose fibroblasts: an epithelial-stromal interaction in breast tumors mediated by CCAAT/enhancer binding protein beta. Cancer Research $2001612328-2334$.

12 Zhao Y, Agarwal VR, Mendelson CR \& Simpson ER. Estrogen biosynthesis proximal to a breast tumor is stimulated by PGE2 via cyclic AMP, leading to activation of promoter II of the CYP19 (aromatase) gene. Endocrinology 1996137 5739-5742. (https://doi. org/10.1210/endo.137.12.8940410)

13 Kim EK, Kim HA, Koh JS, Kim MS, Kim KI, Lee JI, Moon NM, Ko E \& Noh WC. Phosphorylated S6K1 is a possible marker for endocrine therapy resistance in hormone receptor-positive breast cancer. Breast Cancer Research and Treatment 2011126 93-99. (https://doi. org/10.1007/s10549-010-1315-z)

14 Al-Qahtani SM, Bryzgalova G, Valladolid-Acebes I, Korach-Andre M, Dahlman-Wright K, Efendic S, Berggren PO \& Portwood N. 17Betaestradiol suppresses visceral adipogenesis and activates brown adipose tissue-specific gene expression. Hormone Molecular Biology and Clinical Investigation 201729 13-26. (https://doi.org/10.1515/hmbci2016-0031)

15 Jeong S \& Yoon M. 17Beta-estradiol inhibition of PPARgammainduced adipogenesis and adipocyte-specific gene expression. Acta Pharmacologica Sinica 201132 230-238. (https://doi.org/10.1038/ aps.2010.198)

16 Brouckaert O, Rudolph A, Laenen A, Keeman R, Bolla MK, Wang Q, Soubry A, Wildiers H, Andrulis IL, Arndt V, et al. Reproductive profiles and risk of breast cancer subtypes: a multi-center caseonly study. Breast Cancer Research 201719 119-119. (https://doi. org/10.1186/s13058-017-0909-3)

17 Simpson ER, Mahendroo MS, Means GD, Kilgore MW, Hinshelwood MM, Graham-Lorence S, Amarneh B, Ito Y, Fisher CR \& Michael MD. Aromatase cytochrome P450, the enzyme responsible for estrogen biosynthesis. Endocrine Reviews 199415 342-355. (https://doi.org/10.1210/edrv-15-3-342)

18 Chetrite GS, Cortes-Prieto J, Philippe JC, Wright F \& Pasqualini JR. Comparison of estrogen concentrations, estrone sulfatase and aromatase activities in normal, and in cancerous, human breast tissues. Journal of Steroid Biochemistry and Molecular Biology 200072 23-27. (https://doi.org/10.1016/S0960-0760(00)00040-6)

19 Geisler J, Berntsen H \& Lúnning PE. A novel HPLC-RIA method for the simultaneous detection of estrone, estradiol and estrone sulphate levels in breast cancer tissue. Journal of Steroid Biochemistry and Molecular Biology 200072 259-264. (https://doi.org/10.1016/S09600760(00)00036-4)

20 Riggs BL \& Hartmann LC. Selective estrogen-receptor modulators - mechanisms of action and application to clinical practice. New England Journal of Medicine 2003348 618-629. (https://doi. org/10.1056/NEJMra022219) 
21 Paluch-Shimon S, Pagani O, Partridge AH, Abulkhair O, Cardoso MJ, Dent RA, Gelmon K, Gentilini O, Harbeck N, Margulies A, et al. ESO-ESMO 3rd international consensus guidelines for breast cancer in young women (BCY3). Breast 201735 203-217. (https://doi. org/10.1016/j.breast.2017.07.017)

22 Walshe JM, Denduluri N \& Swain SM. Amenorrhea in premenopausal women after adjuvant chemotherapy for breast cancer. Journal of Clinical Oncology 200624 5769-5779. (https://doi.org/10.1200/ JCO.2006.07.2793)

23 Parulekar WR, Day AG, Ottaway JA, Shepherd LE, Trudeau ME, Bramwell V, Levine M, Pritchard KI \& National Cancer Institute of Canada Clinical Trials Group. Incidence and prognostic impact of amenorrhea during adjuvant therapy in high-risk premenopausal breast cancer: analysis of a National Cancer Institute of Canada Clinical Trials Group study - NCIC CTG. Journal of Clinical Oncology 200523 6002-6008. (https://doi.org/10.1200/JCO.2005.07.096)

24 Wolff AC, Hammond MEH, Allison KH, Harvey BE, Mangu PB, Bartlett JMS, Bilous M, Ellis IO, Fitzgibbons P, Hanna W, et al. Human epidermal growth factor receptor 2 testing in breast cancer: American Society of Clinical Oncology/College of American Pathologists clinical practice guideline focused update. Journal of Clinical Oncology 201836 2105-2122. (https://doi.org/10.1200/JCO.2018.77.8738)

25 Sickles EA, D'Orsi CJ, Bassett LW, Appleton CM, Berg WA \& Burnside ESJR. ACR BI-RADS® Atlas, Breast Imaging Reporting and Data System, pp 39-48. Reston, VA, USA: American College of Radiology, 2013.

26 Purohit A, Newman SP \& Reed MJ. The role of cytokines in regulating estrogen synthesis: implications for the etiology of breast cancer. Breast Cancer Research 20024 65-69. (https://doi.org/10.1186/bcr425)

27 Deng T, Lyon CJ, Bergin S, Caligiuri MA \& Hsueh WA. Obesity, inflammation, and cancer. Annual Review of Pathology 201611 421-449. (https://doi.org/10.1146/annurev-pathol-012615-044359)

28 Karlsson E, Magic I, Bostner J, Dyrager C, Lysholm F, Hallbeck AL, Stal O \& Lundstrom P. Revealing different roles of the mTOR-targets S6K1 and S6K2 in breast cancer by expression profiling and structural analysis. PLoS ONE 201510 e0145013. (https://doi.org/10.1371/ journal.pone.0145013)

29 Um SH, Frigerio F, Watanabe M, Picard F, Joaquin M, Sticker M, Fumagalli S, Allegrini PR, Kozma SC, Auwerx J, et al. Absence of S6K1 protects against age- and diet-induced obesity while enhancing insulin sensitivity. Nature 2004431 200-205. (https://doi. org/10.1038/nature02866)
30 Yi SA, Um SH, Lee J, Yoo JH, Bang SY, Park EK, Lee MG, Nam KH, Jeon YJ, Park JW, et al. S6K1 phosphorylation of H2B mediates EZH2 trimethylation of H3: a determinant of early adipogenesis. Molecular Cell 201662 443-452. (https://doi.org/10.1016/j. molcel.2016.03.011)

31 Carnevalli LS, Masuda K, Frigerio F, Le Bacquer O, Um SH, Gandin V, Topisirovic I, Sonenberg N, Thomas G \& Kozma SC. S6K1 plays a critical role in early adipocyte differentiation. Developmental Cell 201018 763-774. (https://doi.org/10.1016/j. devcel.2010.02.018)

32 Clyne CD, Speed CJ, Zhou J \& Simpson ER. Liver receptor homologue-1 (LRH-1) regulates expression of aromatase in preadipocytes. Journal of Biological Chemistry 2002277 20591-20597. (https://doi.org/10.1074/jbc.M201117200)

33 Noh WC, Lee jW, Nam SJ, Park S, Im S-A, Lee ES, Jung Y, Yoon JH, Kang SS, Lee S, et al. Role of adding ovarian function suppression to tamoxifen in young women with hormone-sensitive breast cancer who remain premenopausal or resume menstruation after chemotherapy: the ASTRRA study. Journal of Clinical Oncology 2018 36 502-502. (https://doi.org/10.1200/JCO.2018.36.15_suppl.502)

34 Francis PA, Pagani O, Fleming GF, Walley BA, Colleoni M, Lãng I, Gõmez HL, Tondini C, Ciruelos E, Burstein HJ, et al. Tailoring adjuvant endocrine therapy for premenopausal breast cancer. New England Journal of Medicine 2018379 122-137. (https://doi. org/10.1056/NEJMoa1803164)

35 Hershman DL, Kushi LH, Shao T, Buono D, Kershenbaum A, Tsai WY, Fehrenbacher L, Lin Gomez SL, Miles S \& Neugut AI. Early discontinuation and nonadherence to adjuvant hormonal therapy in a cohort of 8,769 early-stage breast cancer patients. Journal of Clinical Oncology 201028 4120-4128. (https://doi.org/10.1200/ JCO.2009.25.9655)

36 Neugut AI, Subar M, Wilde ET, Stratton S, Brouse CH, Hillyer GC, Grann VR \& Hershman DL. Association between prescription co-payment amount and compliance with adjuvant hormonal therapy in women with early-stage breast cancer. Journal of Clinical Oncology 201129 2534-2542. (https://doi.org/10.1200/ JCO.2010.33.3179)

37 Murphy CC, Bartholomew LK, Carpentier MY, Bluethmann SM \& Vernon SW. Adherence to adjuvant hormonal therapy among breast cancer survivors in clinical practice: a systematic review. Breast Cancer Research and Treatment 2012134 459-478. (https://doi.org/10.1007/ s10549-012-2114-5)

Received in final form 15 May 2019

Accepted 5 June 2019
This work is licensed under a Creative Commons Attribution-NonCommercial 4.0 International License. ded from Bioscientifica.com at 04/26/2023 02:16:30PM 